\title{
Avaliação de métodos de esterilização, concentração de ágar e composição de meio de cultura para propagação in vitro de Pimpinella anisum (Linn.) - Apiaceae
}

\section{Evaluation of asepsis, agar concentration and culture medium composition methods for in vitro propagation of Pimpinella anisum (Linn.) - Apiaceae}

\author{
Gabriela Tambosi ${ }^{1 *}$; Gladys Daniela Rogge-Renner ${ }^{2}$
}

\section{Resumo}

Pimpinella anisum é uma planta popularmente utilizada como medicinal para diversas enfermidades, embora não existam estudos que comprovem sua atividade farmacológica. A espécie não apresenta metodologias conhecidas de assepsia e condições adequadas para experimentos de propagação in vitro. Para avaliar a forma mais eficiente de esterilização de sementes da espécie e melhores concentrações de ágar e sais do meio MS, foram feitos cinco testes de assepsia, bem como testes de avaliação do aumento de massa seca a partir de sementes germinadas em ágar 3g/L e $6 \mathrm{~g} / \mathrm{L}$ e MS nas concentrações $0 \%, 25 \%, 50 \%, 75 \%$ e $100 \%$. A imersão em solução hipoclorito de sódio $2 \%$ por 20 minutos e lavagem em água destilada promoveu $100 \%$ de plântulas estéreis. O maior aumento de massa seca foi obtido com concentração de sais do meio MS de $75 \%$ e $100 \%$, e as diferentes concentrações de ágar não influenciaram a obtenção de maior percentual de massa de plântulas cultivadas.

Palavras-chave: Anis. Micropropagação. Assepsia. Nutrição.

\begin{abstract}
Pimpinella anisum, is a plant species popularly used as treatment for different diseases, although no studies exist which could prove its pharmacological activity. This species has no known methods of asepsis and adequate conditions to conduct in vitro propagation trials. To assess the most efficient method of seed sterilization and the most favorable concentration of agar and MS salts, five tests of asepsis and tests to evaluate the dry mass increase of germinated seed in $3 \mathrm{~g} / \mathrm{L}$ and $6 \mathrm{~g} / \mathrm{L}$ of agar and MS in concentrations of $0 \%, 25 \%, 50 \%, 75 \%$ and $100 \%$, were carried out. The samples that were immersed in a concentration of $2 \%$ sodium hypochlorite for 20 minutes and then washed in distilled water produced $100 \%$ of sterile plantlets. The greatest increase in dry mass was obtained with $75 \%$ and $100 \%$ of MS salts. Furthermore, the different concentrations of agar did not influence the percentage of the plantlets dry mass.

Key-words: Anise. Micro-propagation. Asepsis. Nutrition.
\end{abstract}

\footnotetext{
1 Acadêmica do curso de Farmácia, bolsista de iniciação científica da UNIVILLE. E-mail: gabitambosi@yahoo.com.br

* Autor para correspondência

2 Professora do Departamento de Farmácia e Ciências Biológicas da UNIVILLE.
} 


\section{Introdução}

Pimpinella anisum, da Família Apiaceae, conhecida popularmente pelo nome de anis, é uma espécie vegetal encontrada em Santa Catarina, nativa da Europa (LORENZI; MATOS, 2002) e é utilizada popularmente para prisão de ventre, dor de estômago, cólica intestinal, como antiespasmódico, carminativo, expectorante, tônico estomacal, digestivo, e regularizador das funções menstruais (COELHO; SILVA, 2003; BRICKS, 2002; MATHIAS et al., 1972).

Os fatores ambientais como altitude, latitude, temperatura, umidade relativa do ar, duração do dia, solo, disponibilidade de água e nutrientes influenciam a produção de princípios ativos pelas plantas. A espécie Pimpinella anisum, de acordo com a latitude (distância de determinada região em relação à linha do Equador, para o Sul ou para o Norte), pode ter o crescimento afetado. A espécie é originária do Hemisfério Norte, portanto pode não florescer ou não frutificar no Hemisfério Sul (BRASIL, 2006).

A propagação in vitro consiste em uma técnica para propagar plantas dentro de tubos de ensaios ou similares de vidro, com a devida assepsia, nutrição e fatores ambientais. Tem importância prática na área florestal, agrícola, e científica básica. Para o cultivo asséptico de sementes in vitro, são necessários métodos eficientes de esterilização, visto que, sem ela, o crescimento pode ser inibido ou afetado (CID, 2001).

$\mathrm{Na}$ literatura, os trabalhos que envolvem técnicas de propagação in vitro apresentam o uso de compostos como hipoclorito de sódio em concentrações e por tempos variados (PASSOS et al., 2004; MOURAet al., 2001; SOUZA; GONÇALVES; MACHADO NETO, 1999) e cefalexina (REIS; COSTA; LAMEIRA, 2003). Esses compostos são associados ou não a lavagens prévias com álcool e adição de tensoativo polissorbato como Tween para reduzir a tensão superficial, o que potencializa a ação antimicrobiana das soluções (REIS; COSTA; LAMEIRA, 2003).

Segundo Cid (2001), para o explante crescer in vitro, é necessário que receba nutrientes favoráveis ao seu desenvolvimento, por isso, ele é inoculado em um meio de cultura contendo água e sais. Um dos meios de cultivo mais utilizados é chamado MS (MURASHIGE; SKOOG, 1962), que contém macronutrientes tais quais fósforo, magnésio, e micronutrientes como manganês, cobre, e outros. Componentes orgânicos, como sacarose, inositol, e vitaminas, também constituem um meio nutritivo e sua concentração varia de acordo com a espécie.

Os agentes gelificantes são necessários, considerando que as plantas obtidas devem ficar sobre um suporte, para não afundarem. O ágar-ágar é um tipo de agente gelificante de natureza polissacarídica produzido por algas (Gelidium amansii) (CID, 2001).

Com o intuito de investigar as condições favoráveis para o cultivo de Pimpinella anisum, buscou-se neste trabalho verificar o melhor método de assepsia, as menores concentrações de sais do meio MS que proporcionassem a maior massa seca de plântulas obtidas, e a concentração de ágar mais favorável à fixação da planta, obtendo-se, assim, um menor custo no cultivo.

\section{Materiais e métodos}

As sementes de $P$. anisum foram adquiridas comercialmente, e armazenadas em frascos de vidro sob refrigeração a $4^{\circ} \mathrm{C}$ (RANDI, 1987). Foram testadas diferentes concentrações de sais de meio MS (0\%, 25\%, 50\%, 75\% e $100 \%)$ solidificadas em 3,0 g.L $\mathrm{L}^{-1}$ e 6,0 g.L $\mathrm{L}^{-1}$ de ágar. Os testes para verificar a melhor assepsia das sementes de anis foram os seguintes:

A) Desinfestação com álcool a $70 \%$, por 2 segundos, e em solução de hipoclorito de sódio a $0,5 \%$, por 15 minutos. Em seguida, lavagem por quatro vezes em água destilada autoclavada e imersão em cefalexina 500ppm por 10 minutos (REIS; COSTA; LAMEIRA, 2003).

B) Desinfestação com álcool a $70 \%$ por 2 segundos e em solução de hipoclorito de sódio a 1\%, 
por 15 minutos. Em seguida, lavagem por quatro vezes em água destilada autoclavada e imersão em cefalexina 500ppm por 20 minutos (REIS; COSTA; LAMEIRA, 2003).

C) Imersão em solução de hipoclorito de sódio (2,5\%) e água (2:1), por 20 minutos (MOURA et al., 2001).

D) Imersão em solução de hipoclorito de sódio 2\% durante 20 minutos e lavagem em água destilada estéril (SOUZA; GONÇALVES; MACHADO NETO, 1999).

E) Lavagem inicial em solução de $50 \mathrm{~mL}$ de água com 2 gotas de Tween 20, posterior enxágue em água corrente, e imersão em álcool a $70 \%$ por 40 segundos (PASSOS et al., 2004).

Os procedimentos foram realizados em câmara de segurança biológica e, após cada tratamento de assepsia, foram inoculadas 15 sementes em cada frasco do tipo "baby food" esterilizado, contendo 20 $\mathrm{mL}$ meio de cultivo MS (MURASHIGE; SKOOG, 1962), na concentração de $100 \%$ e ágar a $6,0 \mathrm{~g} \cdot \mathrm{L}^{-1}$ (pH ajustado para 5,8), tampados com tampa plástica e vedados com filme de PVC. O cultivo ocorreu no laboratório de Microbiologia da UNIVILLE (Joinville - SC), com 4 repetições, sendo 15 sementes em cada repetição. O fotoperíodo aproximado foi de 16 horas de luz, fornecida por lâmpadas fluorescentes e temperatura em torno de $25^{\circ} \mathrm{C} \pm 3^{\circ} \mathrm{C}$. O cultivo ocorreu durante 30 dias, com observações diárias, e após esse período avaliou-se o percentual de sementes estéreis, sendo consideradas livres de contaminação aquelas que não apresentaram mudança de coloração ou turbidez do meio de cultivo, e se mantiveram isentas de fungos visíveis a olho nu.

As sementes de $P$. anisum esterilizadas de acordo com o método $\mathrm{D}$ foram submetidas aos testes de concentração de sais do meio MS e ágar. Foram cultivadas em frascos contendo meio MS (MURASHIGE; SKOOG, 1962) nas concentrações $0 \%$ (controle), $25 \%, 50 \%, 75 \%$ e $100 \%$, solidificado com 3,0 e 6,0 g.L $\mathrm{L}^{-1}$ de ágar. O cultivo ocorreu em frascos tipo "baby food", com quatro repetições de cada tratamento, contendo 15 sementes cada repetição. A avaliação foi feita diariamente pela observação dos frascos, considerando germinação a protusão da raiz primária. As plântulas germinadas foram mantidas in vitro por 60 dias, e a verificação da presença de contaminação foi feita visualmente, e foi considerada contaminada aquela que apresentasse mudança de coloração do meio de cultivo, turbidez do meio e presença de fungos visíveis a olho nu. Após os 60 dias de cultivo, as plântulas foram avaliadas quanto ao seu aumento de massa seca (após desidratação em estufa por $48 \mathrm{~h}$ a $30^{\circ} \mathrm{C}$ ). Os resultados obtidos foram submetidos à análise de variância e teste $\mathrm{T}$, ao nível de significância de $1 \%$.

\section{Resultados e discussão}

Os resultados demonstram que em 30 dias de cultivo, o tratamento no hipoclorito de sódio a $2 \%$, durante 20 minutos, e lavagem em água destilada estéril (experimento D) proporcionou 100\% de sementes estéreis (Figura 1). Sendo os percentuais de plântulas estéreis significativamente diferentes entre os tratamentos de esterilização, o método D demonstrou-se o mais eficiente para assepsia de sementes de $P$. anisum. Esse fato pode ser atribuído ao grande potencial antimicrobiano do agente antiséptico utilizado (hipoclorito de sódio), que penetra na parede celular das bactérias, e desativa uma enzima essencial à sobrevivência dos microorganismos (MEYER, 1994). Também cabe levar em conta a alta concentração do mesmo na solução $(2 \%$, hipoclorito de sódio comercial puro) e o maior tempo de imersão (20 minutos), quando se comparam os procedimentos utilizados com os métodos de Moura et al. (2001), Souza, Gonçalves e Machado Neto (1999), Passos et al. (2004) e Reis, Costa e Lameira (2003).

No método C descrito por Moura et al. (2001), embora o agente anti-séptico e o tempo de imersão sejam os mesmos, o potencial de antissepsia pode ter 
sido diminuído devido à diluição da solução em água (Figura 1).

Os métodos citados por Reis, Costa e Lameira (2003), consistiram da desinfestação com álcool $70 \%$, por 2 segundos, e em solução de hipoclorito de sódio seguido de lavagem em água destilada autoclavada e imersão em cefalexina 500ppm. Com esses métodos, observou-se o aumento na concentração do hipoclorito de sódio, aliado ao maior tempo de imersão em cefalexina $(1 \%$ e 20 minutos respectivamente) para o método $\mathrm{B}$, e isso resultou em um aumento significativo do percentual de plântulas estéreis (Figura 1), em comparação com o método A, que utilizou $0,5 \%$ de hipoclorito de sódio e 10 minutos de imersão em cefalexina. Entretanto, segundo Goodman e Gilman, (2005) a cefalexina é um antimicrobiano que interfere na síntese de peptideoglicano da parede celular das bactérias, portanto não é efetiva contra outras classes de microorganismos, como fungos.

Conforme apresentado na figura 1, a lavagem das sementes em solução de $50 \mathrm{~mL}$ de água com 2 gotas de Tween, com posterior enxágüe em água corrente e imersão em álcool 70\% por 40 segundos (PASSOS

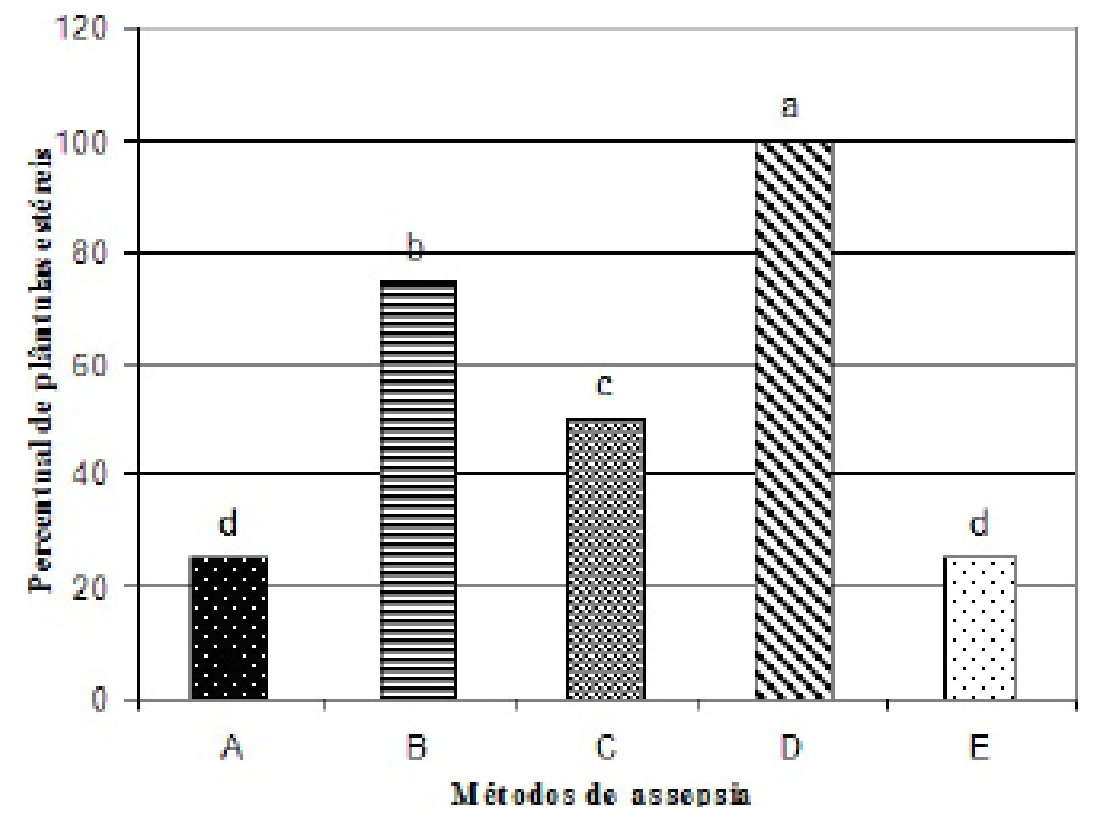

et al., 2004), correspondente ao método E, possuiu baixa eficácia para obtenção de sementes estéreis de P. anisum. Esse fato pode ser explicado devido ao uso de álcool 70\% como único antisséptico após a lavagem inicial, e ao baixo tempo de exposição ao mesmo (40 segundos).

Para os testes de melhor concentração de ágar e meio MS, obtiveram-se os resultados mostrados nas figuras 2 e 3.

O percentual médio de aumento de massa seca não mudou significativamente em função da concentração de MS, fato este comprovado pelo teste T ( $\alpha$ 1\%). Porém observou-se que, ao considerar-se apenas a concentração de ágar no controle (isento de meio MS), a concentração de ágar que favoreceu o aumento de massa seca foi a de $3 \%$.

Por meio das análises, observou-se que a concentração de meio MS influenciou a obtenção de maior massa seca em relação ao controle. As concentrações de MS $75 \%$ e $100 \%$ proporcionaram maior aumento, sem diferenças estatísticas entre si, tanto para a concentração de ágar a 3\%, quanto para a de ágar a $6 \%$.

Figura 1. Eficiência dos testes de assepsia na esterilização de sementes de $P$. anisum. Percentual de plântulas estéreis em 30 dias de cultivo de acordo com cada método. 
As concentrações de 75 e $100 \%$ de meio MS para a concentração de ágar a 3\%, e de 50, 75 e $100 \%$ de meio MS para a concentração de ágar a $6 \%$, proporcionaram maior aumento de massa seca nas plântulas de $P$. anisum (como demonstram as figuras 2 e 3). Isso indica que, além da reserva nutricional que as sementes possuem, a germinação é favorecida com adição de sais do meio MS, devido aos nutrientes presentes no meio MS que suprem as necessidades fisiológicas das sementes, disso resulta a obtenção de maior massa seca de plântulas.

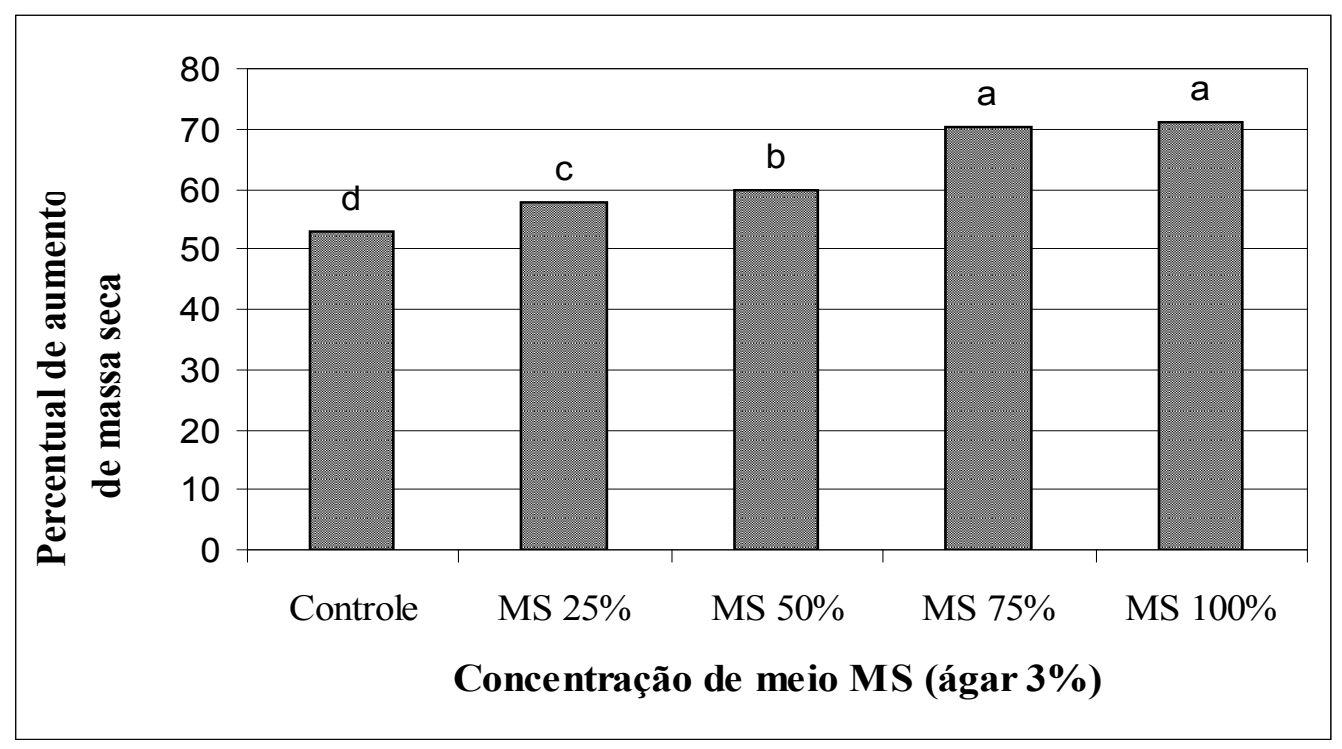

Figura 2. Aumento de massa seca em plântulas de $P$. anisum obtidas após 60 dias de cultivo in vitro em função das concentrações de meio MS para a concentração de ágar 3\%.

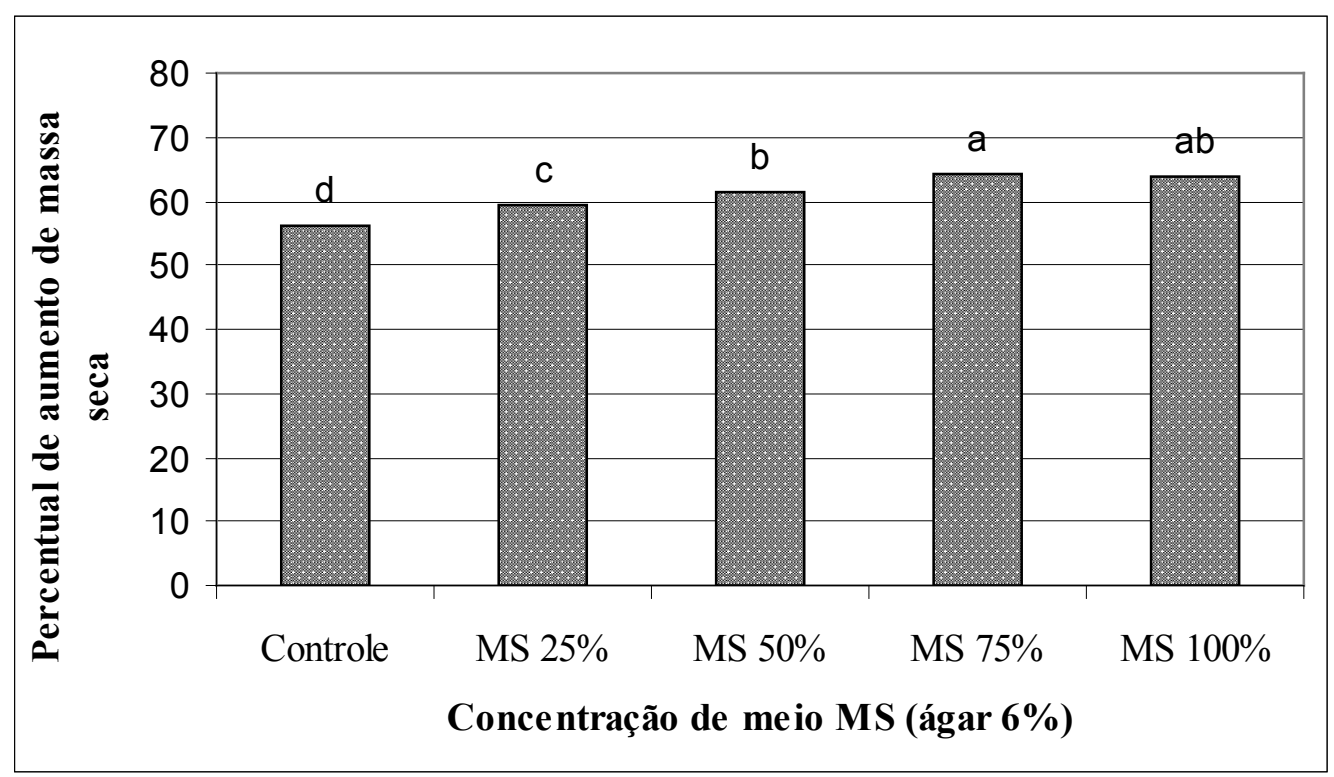

Figura 3. Aumento de massa seca em plântulas de $P$. anisum obtidas após 60 dias de cultivo in vitro em função das concentrações de meio MS para a concentração de ágar $6 \%$. 


\section{Conclusão}

Concluiu-se que o método mais eficiente para a obtenção de sementes estéreis para micropropagação de Pimpinella anisum foi a imersão em solução de hipoclorito de sódio $2 \%$ por 20 minutos e lavagem em água destilada estéril. O maior aumento de massa seca foi obtido com concentração de sais do meio MS de $75 \%$ e $100 \%$, e as diferentes concentrações de ágar não influenciaram a obtenção de maior percentual de massa de plântulas cultivadas.

\section{Agradecimentos}

Os autores agradecem o apoio do Governo do Estado - PIBIC, Artigo 170.

\section{Referências}

BRASIL. Ministério da Agricultura, Pecuária e Abastecimento. Boas práticas agrícolas (BPA) de plantas medicinais, aromáticas e condimentares. Brasília: MAPA/SDC, 2006.

BRICKS, L. F. Choro excessivo e cólica em lactentes. Pediatria, São Paulo, v. 23, n. 4, p. 305-319. 2002.

CID, L. P. B. A propagação in vitro de plantas. O que é isso? Cultura de tecidos vegetais - uma ferramenta fundamental no estudo da biologia moderna de plantas. Biotecnologia Ciência e Desenvolvimento, Brasília, v. 3, n. 19, p. 17-21, 2001.

COELHO, M. F. B.; SILVA, A. C. Plantas de uso medicinal nos municípios de Pontes e Lacerda e de Comodoro, Mato Grosso, Brasil. Revista Agricultura Tropical, Cuiaba, v. 7 n. 1, p. 53-66, 2003.

GOODMAN, L. A.; GILMAN, A. As bases farmacológicas da terapêutica. 10. ed. Rio de Janeiro: McGraw-Hill, 2005.

LORENZI, H.; MATOS, F. J. A. Plantas medicinais no Brasil: nativas e exóticas. Nova Odessa: Instituto Plantarum, 2002.

MATHIAS, M. E.; CONSTANCE, L.; ARAÚJO, D.; KLEIN, R. M.; REITZ, P. R. Umbeliferas. Itajai: Herbário Barbosa Rodrigues, 1972.

MEYER, S. T. O uso de cloro na desinfecção de águas, a formação de trihalometanos e os riscos potenciais à saúde pública. Caderno de Saúde Pública, Rio de Janeiro, v. 10, n. 1, p. 99-110. 1994.
MOURA, T. L.; ALMEIDA, W. A. B.; MENDES, B. M. J.; MOURÃO, F. A. A. Organogênese in vitro de Citrus em função de concentrações de BAP e seccionamento do explante. Revista Brasileira de Fruticultura, Jaboticabal, v. 23, n. 2, p. 24-245, 2001.

MURASHIGE, T.; SKOOG, F. A revised medium for rapid growth and bioassays with tobacco tissue cultures. Physiologia Plantarum, Lund, v. 15, n. 3, p. 473-497, 1962.

PASSOS, I. R. S.; MATOS, G. V. C.; MELETTI, L. M. M.; SCOTT, M. D. S.; BERNACCI, L. C.; VIEIRA, A. R. Utilização do ácido giberélico para a quebra de dormência de sementes de Passiflora nitida Kunth germinadas in vitro. Revista Brasileira de Fruticultura, Jaboticabal, v. 26, n. 2, p. 380-381, 2004.

RANDI, A. M. Aspectos morfogênicos, bioquímicos e citoquímicos durante a germinação de esporos de Cyathea delgadii Stern. 1987. Tese (Doutorado em Fisiologia Vegetal) - Universidade Estadual de Campinas, Faculdade de Ciências Biológicas, Campinas.

REIS, I.N.R.S.; COSTA, M.P.;LAMEIRA, O.A. Métodos de assepsia in vitro de sementes de teca (Tectona grandis). In: SEMINÁRIO DE INICIAÇÃO CIENTÍFICA DA UFRA, 1, SEMINÁRIO DE INICIAÇÃO CIENTÍFICA DA EMBRAPA AMAZÔNIA ORIENTAL, 7., 2003, Belém. Anais. Belém: Universidade Federal Rural da Amazônia, 2003. p. 1-4.

SOUZA, G. M.; GONÇALVES, A. N.; MACHADO NETO, N. B. Crescimento in vitro de progênies de Eucalyptus camaldulensis Dehn. sob condições de deficiência hídrica. Revista Scientia Agrícola, Piracicaba, v. 56, n. 3, p. 557-562, 1999.

Recebido em: 15 de abril de 2009

Aceito em: 29 de novembro de 2010 